\title{
Focusing on butterfly eyespot focus: uncoupling of white spots from eyespot bodies in nymphalid butterflies
}

\author{
Masaki Iwata and Joji M. Otaki
}

\begin{abstract}
Background: Developmental studies on butterfly wing color patterns often focus on eyespots. A typical eyespot (such as that of Bicyclus anynana) has a few concentric rings of dark and light colors and a white spot (called a focus) at the center. The prospective eyespot center during the early pupal stage is known to act as an organizing center. It has often been assumed, according to gradient models for positional information, that a white spot in adult wings corresponds to an organizing center and that the size of the white spot indicates how active that organizing center was. However, there is no supporting evidence for these assumptions. To evaluate the feasibility of these assumptions in nymphalid butterflies, we studied the unique color patterns of Calisto tasajera (Nymphalidae, Satyrinae), which have not been analyzed before in the literature.

Results: In the anterior forewing, one white spot was located at the center of an eyespot, but another white spot associated with either no or only a small eyespot was present in the adjacent compartment. The anterior hindwing contained two adjacent white spots not associated with eyespots, one of which showed a sparse pattern. The posterior hindwing contained two adjacent pear-shaped eyespots, and the white spots were located at the proximal side or even outside the eyespot bodies. The successive white spots within a single compartment along the midline in the posterior hindwing showed a possible trajectory of a positional determination process for the white spots. Several cases of focus-less eyespots in other nymphalid butterflies were also presented.

Conclusions: These results argue for the uncoupling of white spots from eyespot bodies, suggesting that an eyespot organizing center does not necessarily differentiate into a white spot and that a prospective white spot does not necessarily signify organizing activity for an eyespot. Incorporation of these results in future models for butterfly wing color pattern formation is encouraged.
\end{abstract}

Keywords: Butterfly, Color pattern, Calisto tasajera, Eyespot, Focus, Morphometry, Nymphalidae, Organizing center, White spot

\section{Background}

Butterflies and moths are a large group of insects called Lepidoptera. Lepidopteran insects are characterized by wings covered with scales and bristles. These scales are variously colored, and a single scale serves as an image unit (or "pixel"). These scales form diverse mosaic color patterns on wings. One group of butterflies that shows

\section{*Correspondence: otaki@sci.u-ryukyu.ac.jp}

The BCPH Unit of Molecular Physiology, Department of Chemistry, Biology and Marine Science, Faculty of Science, University of the Ryukyus, Nishihara, Okinawa 903-0213, Japan highly diverse color patterns is the family Nymphalidae, from which a common overall color pattern was derived as the nymphalid groundplan (Nijhout 1978, 1991, 2001; Otaki 2009, 2012a; Taira et al. 2015). The nymphalid groundplan is composed of three major symmetry systems (the border, central, and basal symmetry systems) and two peripheral systems (wing root and marginal systems), and all five systems are thought to be produced based on the same mechanism (Otaki 2012a; Taira et al. 2015). A unit of a symmetry system in a single wing compartment is composed of a single core element and a pair 
of paracore elements located at the distal and proximal sides of the core element (Otaki 2012a).

Among the symmetry systems, the border symmetry system is probably the most conspicuous in many nymphalid butterflies. It is composed of a border ocellus (an eyespot) as a core element and a pair of parafocal elements (distal and proximal parafocal elements) as paracore elements (Nijhout 1991, 2001; Dhungel and Otaki 2009; Otaki 2009, 2012a). Moving from the center to the peripheral area, a typical eyespot is composed of a white focal spot at the center (often called a "focus"), an inner black disk, a light-colored ring, and an outer black ring. A typical eyespot can be found in the African satyrine butterfly, Bicyclus anynana, one of the most popular species in butterfly biology (Beldade and Brakefield 2002; Carroll et al. 2004). Physical damage at the prospective eyespot focus in Junonia coenia (Nijhout 1980a, 1991), B. anynana (French and Brakefield 1992), Ypthima argus (Otaki et al. 2005a), Junonia orithya (Otaki et al. 2005a), and Junonia almana (Otaki 2011a), together with transplantation experiments (Nijhout 1980a, 1991; French and Brakefield 1995; Brakefield et al. 1996; Beldade et al. 2008), demonstrated that the center of the prospective eyespot behaves as an organizing center for the eyespot during the pupal stage. However, actual eyespots are highly diverse, and various deformations from the typical eyespot pattern occur (Nijhout 1990, 1991; Otaki 2011b). For example, the white focal spot is often missing, and the various rings are often distorted differently in a single eyespot.

Since the last decade of the twentieth century, many candidate genes that could specify eyespots have been identified based on their expression patterns (Carroll et al. 1994; Brakefield et al. 1996; Keys et al. 1999; Brunetti et al. 2001; Reed and Serfas 2004; Monteiro et al. 2006; Saenko et al. 2011; Tong et al. 2012). These genes are expressed during the late larval to the early pupal stages in the wing tissues, which is when the color pattern determination takes place (Nijhout 1980a). Among them, the most notable gene is probably Distal-less $(\mathrm{Dll})$. It has been shown that $D l l$ expression recapitulates the locations of organizing centers that were predicted by a reaction-diffusion model (Carroll et al. 1994; Nijhout 1990, 1991, 1994, 1996), which has often been interpreted as meaning that $D l l$ expression defines an organizing center and that $D l l$ is a master gene for eyespot determination. In addition to the eyespot focal determination, it has also been suggested that $\mathrm{Dll}$ determines eyespot size (Brakefield et al. 1996; Beldade et al. 2002).

However, functional tests for $D l l$ were not performed until recently. One study using transgenic $B$. anynana butterflies showed that $D l l$ plays a role in eyespot size regulation as well as in black spot induction (Monteiro et al. 2013). One study using the blue pansy butterfly,
J. orithya, together with a novel surgical technique, showed a weak correlation of the individual $\mathrm{Dll}$ expression level with the individual eyespot size (Adhikari and Otaki 2016). However, sexually dimorphic eyespot size in this species (i.e., female eyespots are larger than male ones) cannot be explained by the Dll expression levels; female forewings have lower $D l l$ levels than male ones (Adhikari and Otaki 2016). Subsequently, using J. orithya with a baculovirus gene transfer method (Dhungel et al. 2013), it has been shown that $D l l$ can induce fragmentary patterns of an eyespot but not an entire eyespot (Dhungel et al. 2016). More elegantly, $D l l$ deletion using genome editing has produced a deformation of eyespot, an increase of eyespot number and size, and an emergence of dark patches in Vanessa cardui and J. coenia, suggesting a role of $D l l$ in eyespot repression (Zhang and Reed 2016). Taken together, although $D l l$ is unlikely to be sufficient for the entire eyespot pattern formation, it plays an important role in eyespot development.

Morphological studies also advanced. Butterfly wings exhibit coordinated scale size distributions in addition to coordinated scale color distributions (Kusaba and Otaki 2009; Dhungel and Otaki 2013; Iwata and Otaki 2016). The largest scales in an eyespot are often at the central area in J. orithya (Kusaba and Otaki 2009) and J. almana (Iwata and Otaki 2016). This finding, together with the observation that scale size is proportional to the size of scale-building cells (Henke 1946; Sondhi 1963), led us to propose the ploidy hypothesis that morphogen signals for color patterns are identical to ploidy signals (Iwata and Otaki 2016).

Additionally, the pupal surface has cuticle focal spots that correspond to adult eyespots in various butterfly species (Nijhout 1980a; Otaki et al. 2005a). Two Junonia species that have large eyespots in adult wings, J. orithya and J. almana, indeed have large and distinct pupal cuticle focal spots, whereas a Junonia species that has small eyespots in adult wings, J. hedonia, has small ones (Taira and Otaki 2016). Interestingly, the size of the cuticle spot is correlated with the size of the corresponding eyespots in J. orithya and Y. argus (Otaki et al. 2005a). Similar correlations were also obtained among serial eyespots on a single wing in J. orithya (Taira and Otaki 2016). The three-dimensional structures of pupal cuticle focal spots as well as adult wings were revealed recently (Taira and Otaki 2016).

Moreover, physiologically induced changes of color patterns, which are typically considered positional and morphological changes of elements, have been investigated in detail (Nijhout 1984; Otaki 1998, 2007, 2008a, b; Otaki and Yamamoto 2004a, b; Serfas and Carroll 2005; Otaki et al. 2005b, 2010; Mahdi et al. 2010, 2011; Hiyama et al. 2012). Meanwhile, an invention of a real-time 
in vivo observation system made it possible to record how wing tissues develop inside the pupal case (Iwata et al. 2014). Developing epithelial cells are elongated vertically as well as horizontally (Ohno and Otaki 2015a), confirming a century-old histological study (Mayer 1896). Long-range slow calcium waves have been discovered in pupal wing tissues, which may function as signals to coordinate development throughout a wing (Ohno and Otaki 2015b).

This information should collectively evaluate the feasibility of mechanistic models for color pattern determination. Historically, morphogen gradient models have been proposed and used to explain various experimental results (Nijhout 1978, 1980a, 1981, 1990, 1991; French and Brakefield 1992, 1995; Brakefield and French 1995; Monteiro et al. 2001; Serfas and Carroll 2005; Otaki 2008a). Nijhout (1990) examined the diverse eyespot patterns of nymphalid butterflies and identified 36 pattern categories, which were used to construct a gradient-based model. These models are based on the simple diffusion of a putative morphogen that forms a gradient, together with differentiation thresholds inherently programmed into immature scale cells. Abrupt changes of the cellular interpretation of a smooth gradient were attained mathematically by a sigmoidal curve, resulting in two thresholds and three colors (Nijhout 1991).

However, Otaki (2011b, c) pointed out several difficulties of the gradient models to explain actual butterfly wing color patterns. For example, an "archetypical" butterfly eyespot is likely composed of a series of repetitions of an inductive signal for black (or dark) area (Otaki 2011c). In other words, a non-black (i.e., light-colored) area between the black areas is equivalent to background (Otaki 2011c). This binary rule (stating that a series of repetitions of dark areas with light-area intervals is the basic expression of an eyespot) alone makes thresholdbased diffusion models unrealistic because the black rings or disks are equivalent to each other in actual butterflies. Moreover, not just two but three or more repetitive black rings are observed in many butterflies (Otaki 2011b). Indeed, one of the "black rings" of an eyespot is a pair of discontinued elements called parafocal elements (Otaki 2009, 2011c, 2012a, b). Moreover, color pattern analysis of neighboring or serial eyespots with different structures on the same wing surface pointed out that thresholds for gradient interpretation, if exist according to the gradient models, do not vary among neighboring compartments and that these eyespots should be produced by different levels of a morphogen to reflect their morphological differences (Otaki 2011b). But it is theoretically difficult to satisfy these two points simultaneously in gradient models (Otaki 2011b). In fact, the dynamic responses of eyespots to physical damage requires flexible models that can accommodate signals from damage sites and from neighboring organizing centers (Otaki 2011a).

As an alternative model, the induction model has been proposed (Otaki 2011b, c, 2012b). The induction model is based on many case analyses of normal and experimentally induced color patterns (Otaki 2011b, c, 2012b), incorporating the principle of "short-range activation and long-range inhibition" that have been found in many biological patterns (Gierer and Meinhardt 1972; Meinhardt 1982; Meinhardt and Gierer 1974, 2000).

In either model, the status of the white focal area has not been explained well in the literature. Nijhout (1978, 1980a) proposed that a "focus" at the center of an eyespot releases a morphogen at the late larval and early pupal stages, based on which a gradient model was formulated. Since then, one tends to assume that the white focal spot directly corresponds to an organizing center for the entire eyespot. In many instances, this assumption seems to be valid; a white spot is located at the physical centers of eyespots in many nymphalid butterflies. However, this is not always the case. Nijhout (1980a) indeed pointed out that the white scales at the eyespot center do not precisely correspond to the "focus". Likewise, there is a discrepancy between the location of the largest scales and the location of the white spots in a particular eyespot of J. almana (Iwata and Otaki 2016). Similar cases have been pointed out in Calisto herophile and other butterflies (Iwata and Otaki 2016). Moreover, the white coloration is structural rather than pigment-based (Nijhout 1980b, 1991; Iwata and Otaki 2016). In a gradient model, the area of the highest morphogen concentration above a certain threshold is supposed to become the white spot. But molecular pathways for structural color production are probably qualitatively different from those for pigment-based color production. Thus, one could think that these two production lines may be distinctly specified. In any case, the relationships between white spots and their corresponding eyespot bodies (defined as all the eyespot portions except white spots) should be clarified to understand how butterfly eyespots are constructed during development.

In this paper, we ask if white spots behave independently of eyespot bodies. We hypothesized that if uncoupling of white spots is mechanistically possible, some species of nymphalid butterflies show uncoupling color patterns naturally. More concretely, we hypothesized that it may be possible to observe white spots that are not located at the center of an eyespot in nymphalid butterfly wings and that such uncoupling behavior may be shown by morphometric analysis. Here, we focus on Calisto butterflies to test this hypothesis.

Lepidopterists in Asian (and probably in many other) countries are not familiar with the genus Calisto because 
they are endemic to the West Indian regions (mainly in Hispaniola, which is occupied by Haiti and Dominican Republic). Indeed, Calisto-type pear-shaped eyespot patterns were not incorporated in the pattern analysis of Nijhout (1990). However, we had an opportunity to examine specimens of Calisto butterflies. The genus Calisto is an exclusive group of satyrine butterflies in the West Indies that constitutes more than 40 species (Smith et al. 1994; Miller and Miller 2001; Askew and Stafford 2008). Among them, we here focused on eyespots of Calisto tasajera González, Schwartz \& Wetherbee 1991 (González et al. 1991; Hedges and Johnson 1994) because it has unique pear-shaped eyespots that have two or more white "focal" spots. Molecular phylogenetic analysis and historical biogeography of Calisto have been reported (Sourakov and Zakharov 2011; Matos-Maraví et al. 2014). We also examined eyespots of other nymphalid butterflies to support our findings with $C$. tasajera. The present study argues for an uncoupling of white spots from the rest of the eyespots (i.e., eyespot bodies).

\section{Methods}

\section{Butterflies}

We primarily analyzed 17 specimens of C. tasajera owned by Nariaki Yamada (The Butterfly Science Society of Japan), Tokyo, Japan (Fig. 1a). These butterflies were collected in the Dominican Republic on July 17, 2002, by Haruo Takizawa (Fig. 1b). Sex of these individuals was not identified; this species is not sexually dimorphic. We focused on three wing regions of the ventral side that contain eyespots and/or white spots: the anterior forewing, the anterior hindwing, and the posterior hindwing (Fig. 1c). The ventral side of the left wings was examined in all cases except for one individual which had left wing damage; in this case, the ventral side of the right wings was examined. Venation patterns of Calisto butterflies are not unique. This means that venation patterns do not confer Calisto butterflies unique color patterns. Specimens of Calisto butterflies (other than C. herophile) are owned by N. Yamada. Other butterfly specimens are owned by the author (J. M. O.).

\section{Images and morphometry}

Images of specimens were taken by an Olympus digital camera STYLUS TG-4 Tough (Tokyo, Japan) using its microscope mode. Areas of white spots and black disks of eyespots in C. tasajera were measured using ImageJ v. 1.48 image analysis software (Schneider et al. 2012). Because we were not allowed to measure absolute values, which potentially damages the specimens, relative values within a single image were used for comparison in this study.

\section{Basic assumptions}

We assumed that a basic molecular mechanism for color pattern formation is shared in all compartments of a single wing surface or at least in two adjacent wing compartments. This is the very basic assumption that is required for this type of color pattern analysis.

In analyzing color patterns, we assumed that morphogenic signals are released from an organizing center and that the signals move equally well in all directions. These

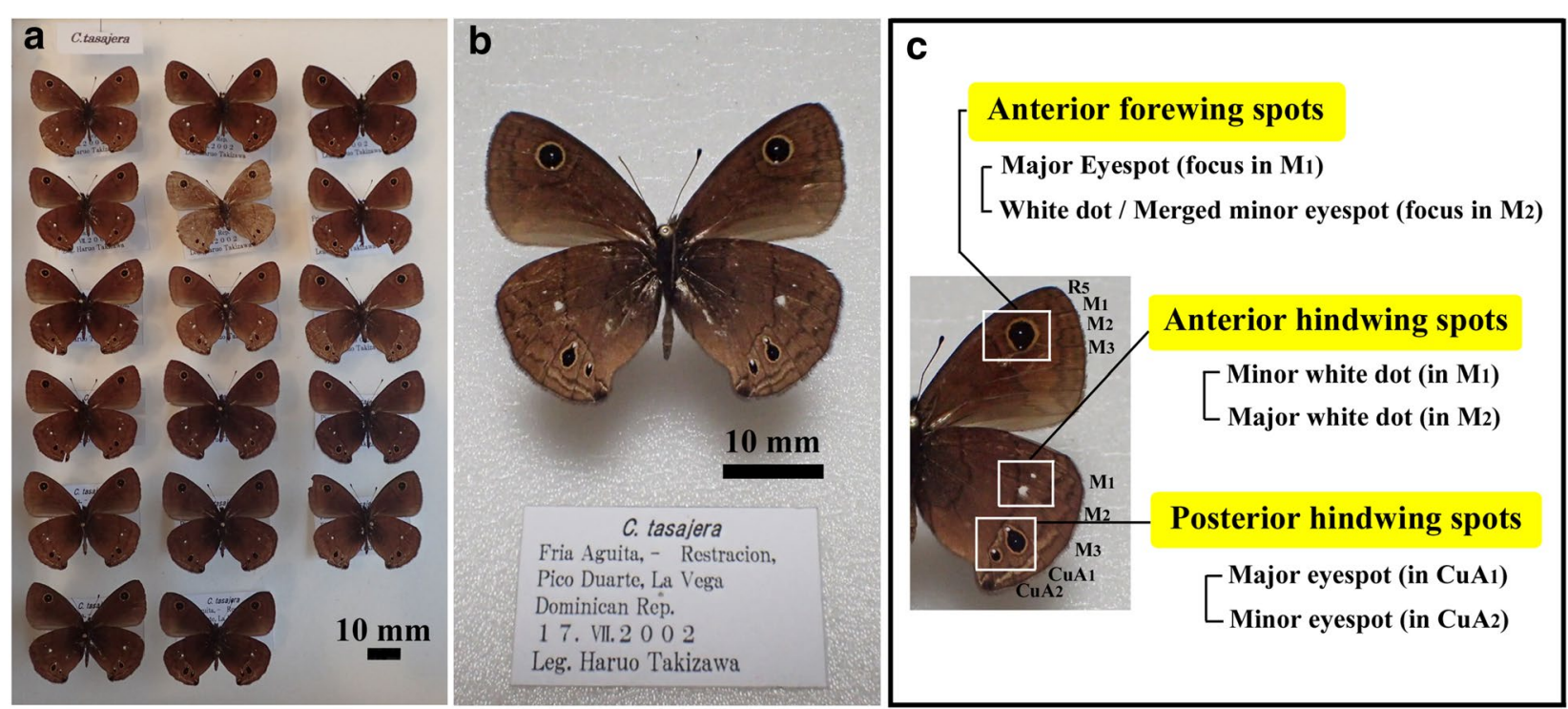

Fig. 1 Specimens of Calisto tasajera. a 17 specimens that were analyzed in this study; b a specimen (one of 17) showing the ventral side; c three regions of analysis on the ventral wings 
assumptions led to the following interpretations. (1) If an eyespot is close to an exact circle, its signals were released from its physical center. (2) If an eyespot is clearly distorted from an exact circle as observed in an oval or pear-shaped eyespot, its signals were released from two or multiple sites, unless there is a nearby element that blocks the propagation of the morphogenic signals. That is, a morphogenic gradient is made as a merge of two or multiple signals.

In discussing a diffusion-based gradient model, it has often been assumed implicitly that a white spot at the center of an eyespot corresponds to an organizing center for the entire eyespot (see "Background"). We do not believe that this assumption is always correct; however, because this assumption is associated with the gradient models, it was used as a starting point of color pattern analysis in the present study. Furthermore, the simplest form of a conventional diffusion-based gradient model predicts that the eyespot focus had the highest concentration of a morphogen in the larval and pupal wings. Accordingly, the area of the highest morphogen concentration corresponds to a white spot. If the threshold level is fixed and not changeable, the higher the level of morphogen that is released, the wider the area of the white spot that is specified by the morphogen.

In making models for color pattern formation, it is often assumed that adult wing color patterns are directly determined by their pre-patterns in pupal wings. For simplicity, this assumption is also followed in the present study. If one considers that color patterns are finalized through a four-step process (signaling, reception, interpretation, and expression) (Otaki 2008a), a pre-pattern may not be realized solely by the signaling step without the subsequent steps of reception, interpretation, and expression. A direct determination of adult color patterns by pre-patterns thus means that these subsequent steps are all normally executed without positional bias. In reality, however, it has been known that the proximal and distal wing surfaces have different sensitivities to morphogenic signals (Nijhout 1978, 1980a, 1985; Brakefield and French 1995; French and Brakefield 1995).

\section{Statistics}

Numerical values were recorded in Microsoft Excel and analyzed with $\mathrm{R}$ statistical software, version 3.2.1 (The R Foundation for Statistical Computing, Vienna, Austria). For each dataset, normality was checked with a Shapiro-Wilk test, based on which nonparametric tests were performed. Mean and standard deviation (SD) values were calculated, and Mann-Whitney $U$ tests (pairwise comparison using Wilcoxon rank sum tests) were performed to compare two samples. When multiple pairwise comparisons were made, $p$ values were adjusted by
Holm correction. The Spearman rank correlation coefficient $\rho$ was obtained to examine the possible correlation between two variables.

\section{Results \\ Anterior forewing spots in C. tasajera}

We first analyzed the color patterns of the anterior forewing spots in $C$. tasajera. A relatively large eyespot was present in the anterior forewing (Fig. 2a-f). The white spot ("focus") of this eyespot was located in the $M_{1}$ compartment, but this eyespot was not confined to the $M_{1}$ compartment; it also occupied two adjacent compartments, $R_{5}$ and $M_{2}$ (Fig. 2). This invading eyespot suggests that immature scale cells in these three compartments were equally receptive to morphogenic signals from the $\mathrm{M}_{1}$ organizing center during the late larval and early pupal stages.

In the $\mathrm{M}_{2}$ compartment, a white spot was present, the size of which was similar to that of the $M_{1}$ compartment. This white spot was located just on the yellow ring or on the edge of the inner black disk, without a significant distortion of the $M_{1}$ eyespot, in 6 individuals out of 17 (Fig. 2a, $\mathrm{e}, \mathrm{f}$ ). In these cases, the $\mathrm{M}_{1}$ eyespot was almost an exact circle. According to a conventional understanding, the central positioning of the white spot within this eyespot suggests that the $M_{1}$ white spot corresponds to the organizing center from which morphogenic signals for the eyespot body were released during development in this particular eyespot. On the other hand, 11 individuals showed a distortion of the $M_{1}$ eyespot; in these cases, the $M_{2}$ white spot was located completely inside the eyespot (Fig. $2 b-d$ ). This likely occurs from a fusion of the smaller $\mathrm{M}_{2}$ eyespot and the larger $M_{1}$ eyespot. Thus, the $M_{1}$ white spot appears to have corresponded to a highly active organizing center and the $\mathrm{M}_{2}$ white spot to either an inactive or less active organizing center.

A close examination of an $M_{1}$ eyespot revealed that there was an outermost weak black ring located outside a yellow ring (Fig. 2e, f). This weak black ring existed all around the yellow ring including the immediate vicinity of the $M_{2}$ white spot in all 6 cases when there was no distortion of the $M_{1}$ eyespot (Fig. 2e, f), suggesting that the $\mathrm{M}_{2}$ white spot in these cases was completely inactive as an organizing center for the eyespot body despite a clear expression of the white scales.

\section{Anterior hindwing spots in C. tasajera}

The anterior hindwing in C. tasajera had two solitary white spots, one in the $\mathrm{M}_{1}$ compartment and the other in the $\mathrm{M}_{2}$ compartment (Fig. 3). In all 17 individuals, the $M_{2}$ white spot was much larger than the $M_{1}$ white spot (Fig. 3a). Moreover, the $\mathrm{M}_{2}$ white spot showed a "sparse pattern" sensu Nijhout (1991). Some of these 

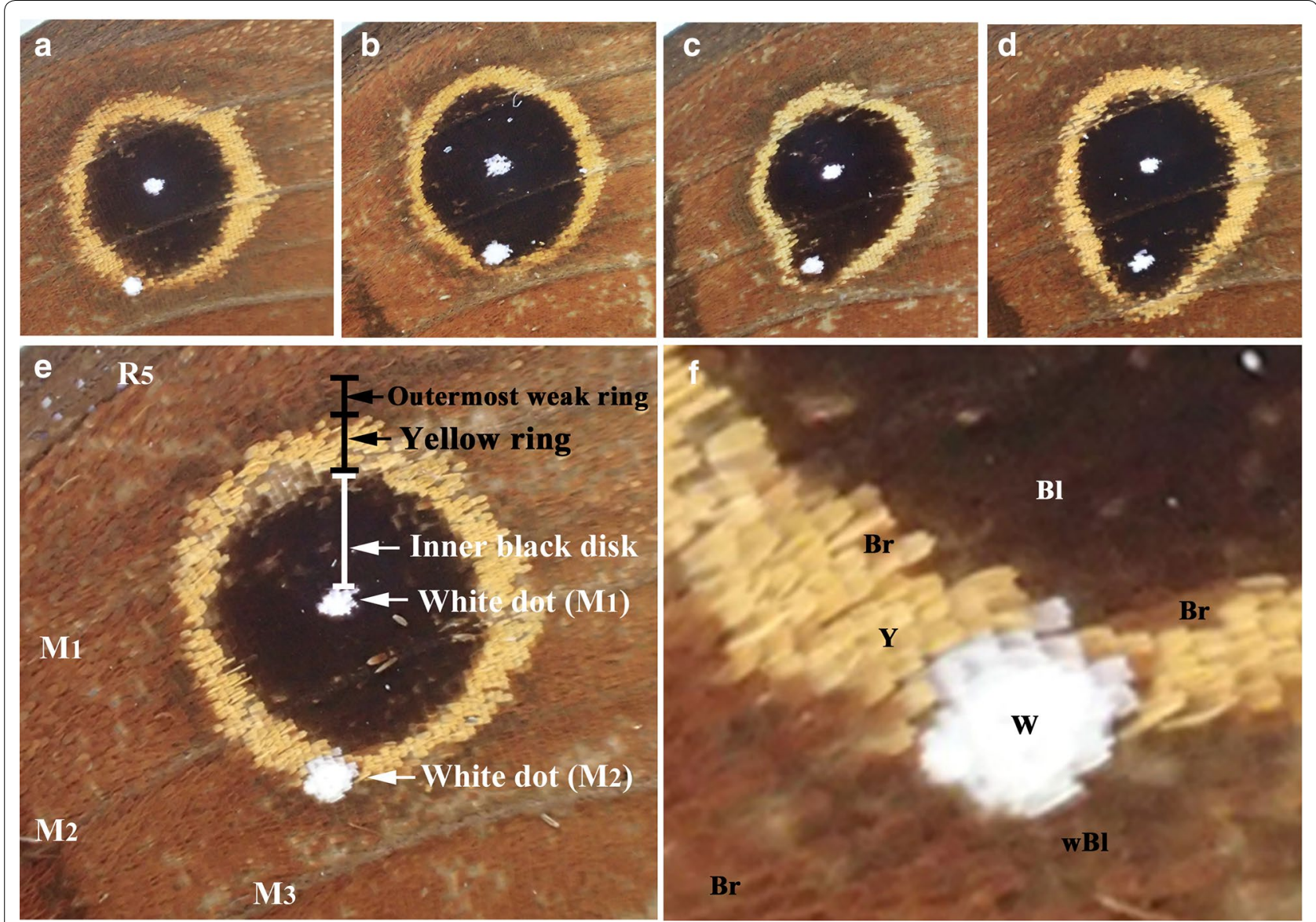

Fig. 2 Anterior forewing spots. a-d Variations of spots. e High magnification image of the anterior forewing spots with annotations. Four wing veins, $R_{5}, M_{1}, M_{2}$, and $M_{3}$, are marked. $\mathbf{f}$ Higher magnification image of e. Scale colors are indicated as follows: W (white), $B I$ (black), $Y$ (yellow), Br (brown), and wBI (weak black)
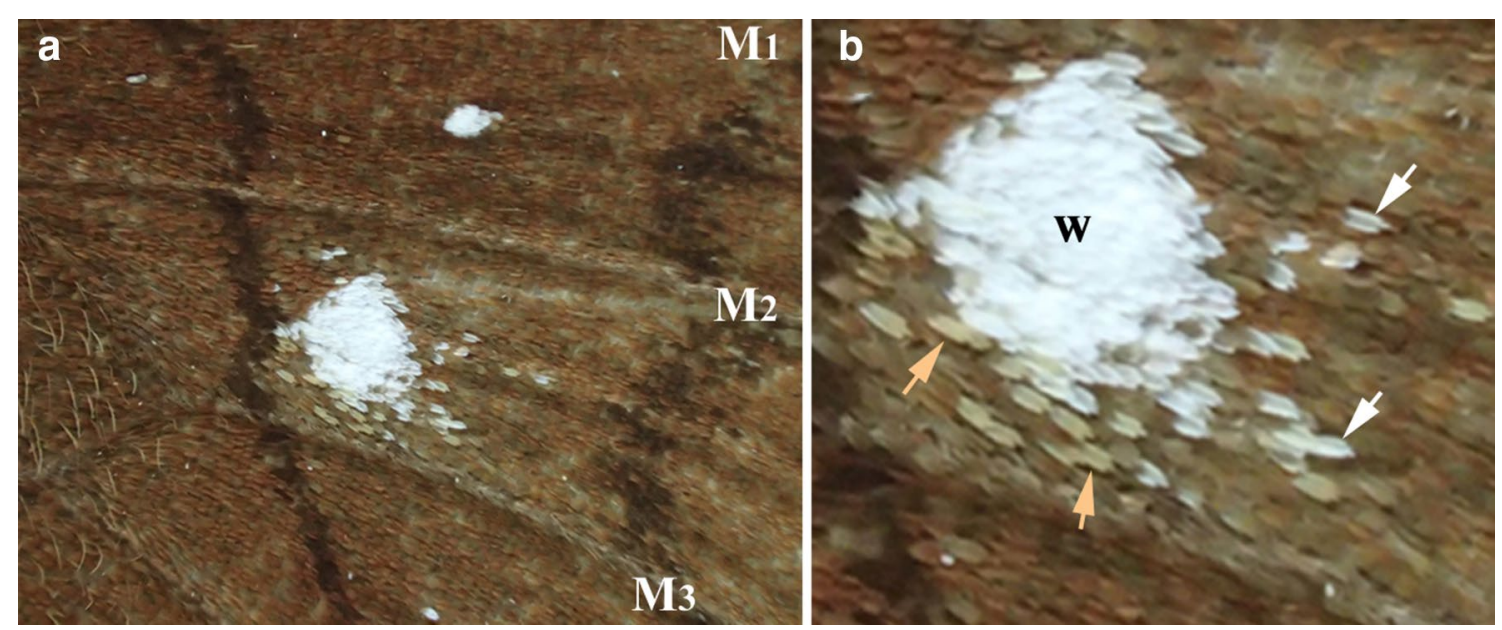

Fig. 3 Anterior hindwing spots. a White spots in the $M_{1}$ and $M_{2}$ compartments. Three wing veins, $M_{1}, M_{2}$, and $M_{3}$, are marked. b High magnification of the white spot in the $\mathrm{M}_{2}$ compartment. The sparse pattern is clearly observed. Some sparse scales are white (white arrows), and other sparse scales are brown (light brown arrows) 
sparse scales were not white but light brown (Fig. 3b). These scales probably contained relatively small amount of brown pigment and developed white structural color simultaneously, suggesting that a decision-making process for differentiation is not all or nothing. Neither the $M_{1}$ nor the $M_{2}$ white spot accompanied any eyespot structure, suggesting that the organizing cells that differentiated into these white spots did not have any eyespot-inducing activity.

\section{Posterior hindwing spots in C. tasajera}

The posterior hindwings of $C$. tasajera had two eyespots, one in the $\mathrm{CuA}_{1}$ compartment and the other in the $\mathrm{CuA}_{2}$ compartment (Fig. 4). Most of the $\mathrm{CuA}_{1}$ eyespots (and
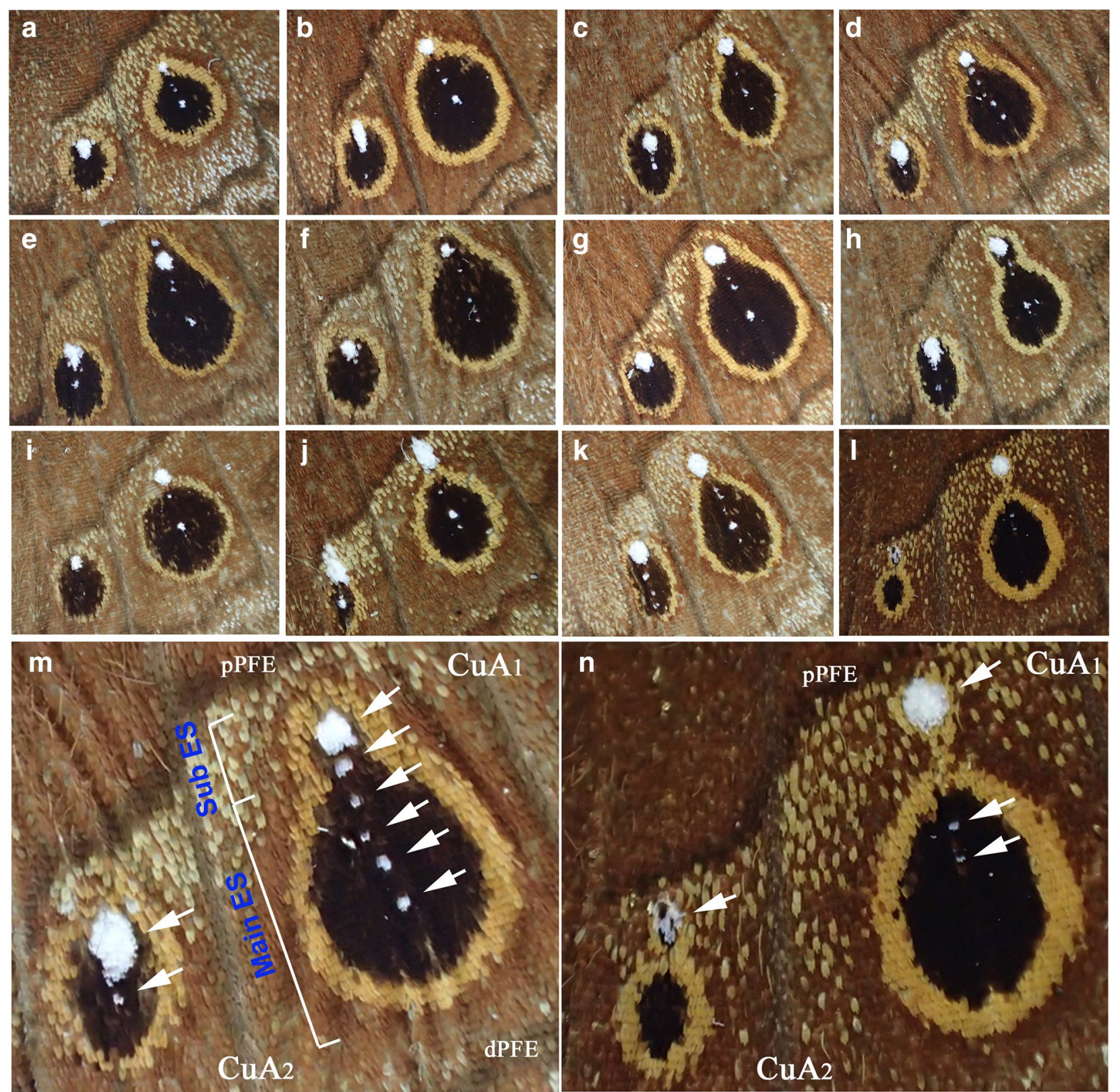

Fig. 4 Posterior hindwing spots. a-IVariations of spots. $\mathbf{m}$ An example of a high magnification image with annotations. Arrows indicate white dots along the midline. The white dots are located within the merged eyespots. The whole structure may be called a pear-shaped eyespot. The sub eyespot (ES) and the main ES are distinctly named. Wing veins CuA $\mathrm{A}_{1}$ and CuA $\mathrm{A}_{2}$ are marked, and parafocal elements, pPFE (proximal PFE) and dPFE (distal $\mathrm{PFE}$ ) are also indicated (also in $\mathbf{n}$ ). $\mathbf{n}$ Another example of a high magnification image. Arrows indicate white dots along the midline. The large white dots are located outside the eyespots in both compartments 
the $\mathrm{CuA}_{2}$ eyespots to a similar degree) were pear-shaped (Fig. 4a-h). These pear-shaped eyespots suggest that morphogenic signals were released from two or more sites within a single compartment. This pear-shaped eyespot morphology can be considered as a merger of two (or more) eyespots: a main eyespot and a sub eyespot (Fig. $4 \mathrm{~m}$ ). In all 17 individuals, the most distinct white spot in these compartments was located at the proximal edge of the eyespot, often with a few small white spots along the midline. The organizing cells for the most proximal white spot did not seem to have been highly active to induce the eyespot body, but the organizing cells for black scales (or the small white dot) at the physical center of the eyespot were probably highly active to induce the eyespot body.

The merger of the main and sub eyespots in the $\mathrm{CuA}_{1}$ and $\mathrm{CuA}_{2}$ compartments is comparable to that in the anterior forewing region. In the anterior forewing region, two organizing centers (specified by the white spots) were located in different compartments. In the case of the posterior hindwing region, two (or more) organizing centers were located in the same compartment along the midline. Interestingly, in 4 individuals out of 17 , the proximal white spot was located outside the eyespot, forming an independent spot (Fig. $4 \mathrm{i}-\mathrm{l}, \mathrm{n}$ ).

\section{Quantitative comparisons of white areas}

The white area ratios were calculated for the anterior forewing region $\left(M_{1} / M_{2}\right)$, the anterior hindwing region $\left(M_{1} /\right.$ $\left.\mathrm{M}_{2}\right)$, and the posterior hindwing region $\left(\mathrm{CuA}_{1} / \mathrm{CuA}_{2}\right)$ of C. tasajera (Fig. 5a). Although the anterior forewing and hindwing regions are homologous, the ratios were significantly different between them $\left(p=2.1 \times 10^{-6}\right)$; in the anterior forewing region, the two white dots were similar in size, showing a ratio of $0.83 \pm 0.29$ (mean \pm SD; also hereafter), but in the anterior hindwing region, the ratio was $0.16 \pm 0.10$. The ratio of the posterior hindwing region was also close to one, $1.09 \pm 0.60$ and was significantly different from that of the anterior hindwing region $\left(p=2.1 \times 10^{-6}\right)$. The ratios between the anterior forewing region and the posterior hindwing regions were not significantly different $(p=0.23)$.

In the posterior hindwing region, the ratio of black area to white area (black/white) in each compartment was calculated to quantitatively understand eyespot constituents. The ratio of the $\mathrm{CuA}_{1}$ compartment, $18.54 \pm 9.49$,

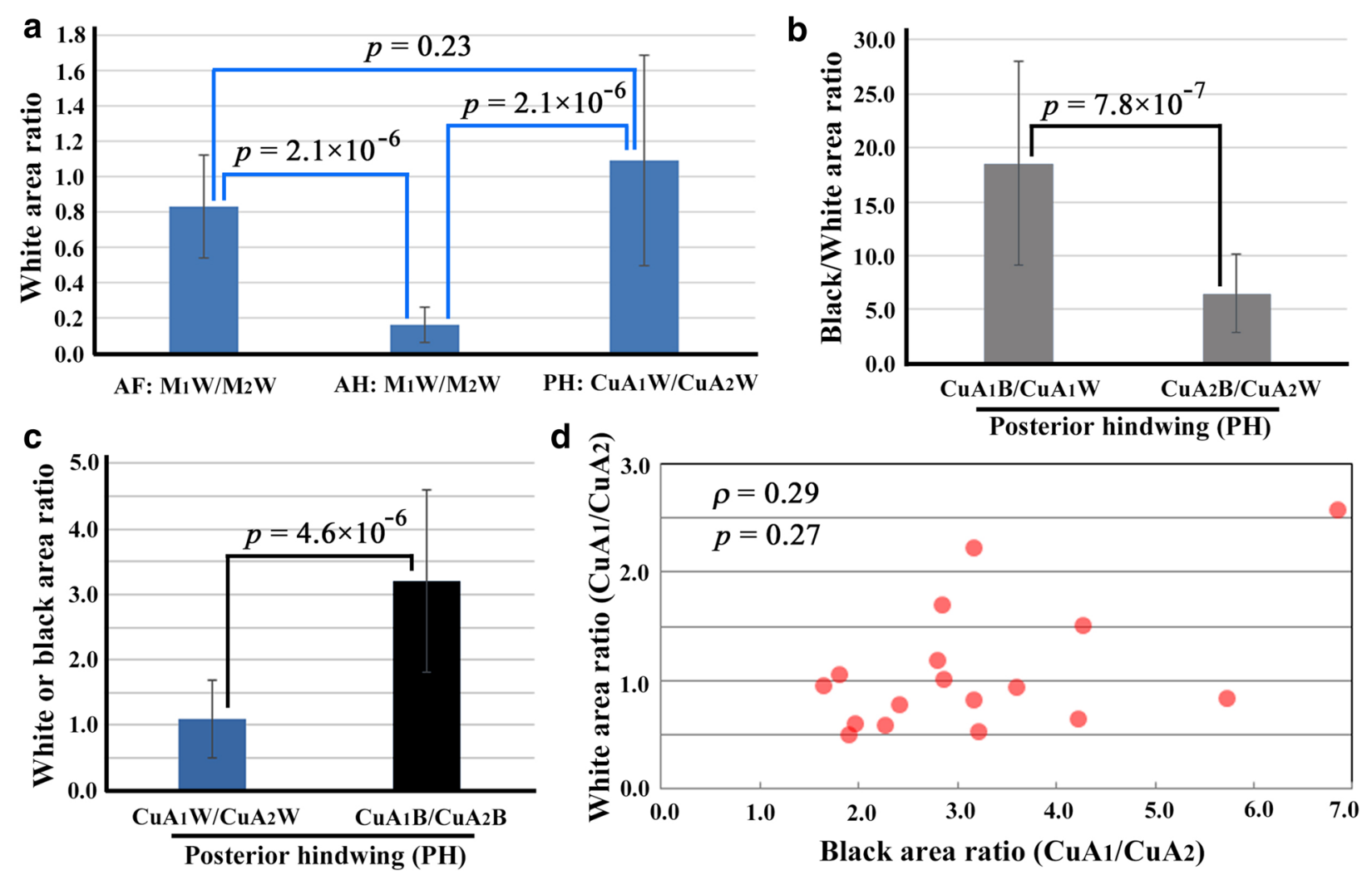

Fig. 5 Quantitative comparisons of area ratios in the anterior forewings (AF), anterior hindwings (AH), and posterior hindwings ( $\mathrm{PH}$ ). Compartmental names with W (white) or B (black) at the end are indicated. a White area ratios among three wing regions. b Black/white ratios in the posterior hindwing region. $\mathbf{c}$ White area ratio versus black area ratio in the posterior hindwing region. $\mathbf{d}$ Scatter plot of black area ratio versus white area ratio 
was significantly larger than that of the $\mathrm{CuA}_{2}$ compartment, $6.46 \pm 3.68\left(p=7.8 \times 10^{-7}\right)$ (Fig. 5b). Then, from a different perspective, the ratio of the white areas between the two compartments and the ratio of the black areas between the two compartments were compared. The white area ratio $(1.09 \pm 0.60)$ and the black area ratio $(3.21 \pm 1.4)$ were significantly different in these two adjacent compartments $\left(p=4.6 \times 10^{-6}\right)$ (Fig. $\left.5 \mathrm{c}\right)$. In 17 individuals, the black area ratio and the white area ratio were not correlated significantly in the Spearman correlation analysis $(\rho=0.29 ; p=0.27$ ) (Fig. $5 \mathrm{~d}$ ).

\section{White spot diversity in Nymphalidae}

Thus far, we have focused on white spot patterns only in C. tasajera. To investigate whether similar white spot patterns are present in other species, we examined specimens of other nymphalid butterflies-including other Calisto species.

We were able to examine five other Calisto species (one specimen per species), all of which showed that the eyespots on the posterior hindwing had a proximal white spot with or without multiple small white spots along the midline. In these five species, we were not able to confirm the morphological features that were found in C. tasajera in the anterior forewings (i.e., a full circular eyespot in a compartment and a solitary white spot in the adjacent compartment) and anterior hindwings (i.e., two adjacent white spots, one of which shows sparse pattern) (Fig. 6).

A white spot on the proximal side (or even outside) of the main eyespot body, as observed in the posterior hindwings of all the Calisto species examined here, is probably not found frequently, but many examples of "focus-less" eyespots were found in other nymphalid butterflies. In the forewings of J. orithya, eyespots both on the dorsal and ventral sides were similar in size and structure, but interestingly, the dorsal eyespots had bluish-white spots at the center, whereas the ventral eyespots did not (Fig. 7a). The opposite was true in Protogoniomorpha temora: the dorsal eyespots had no white spot, whereas most of the ventral eyespots (not all) had white spots (Fig. 7b).

Many other examples of focus-less eyespots on the dorsal side but not in the ventral side were found in satyrine butterflies, including Zophoessa callipteris (Fig. 7c), Kirinia fentoni, Erebia ligea, Neope goschkevitschii, Neope niphonica, and Lopinga achine (Fig. 8a). Among these, $L$. achine is a noteworthy case: some individuals of this species had focus-less eyespots on both sides of the wings (Fig. 8b). The presence or absence of the white spot did not seem to affect the eyespot size in this species.

\section{Discussion}

\section{Uncoupling of white spots from eyespot bodies}

In this paper, we analyzed the eyespots and white spots of C. tasajera. We focused on three regions of ventral wings: the anterior forewing, the anterior hindwing, and the posterior hindwing. In the two adjacent compartments of the anterior forewing, there were a full circular eyespot and a solitary white spot. Also noteworthy is the invasion of the $M_{1}$ eyespot to the adjacent $R_{5}$ and $M_{2}$ compartments, despite the fact that the $\mathrm{M}_{2}$ compartment harbors a white spot (with no or small eyespot body) that is as large as that in the $M_{1}$ eyespot, suggesting that all three compartments had the same sensitivity to morphogenic signals. In the anterior hindwing, we observed different shapes and sizes of the white spots in the two adjacent compartments, neither of which were associated with eyespots. In the posterior hindwing, we observed unique
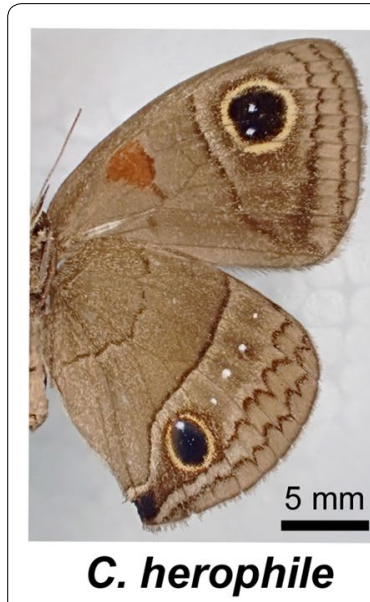

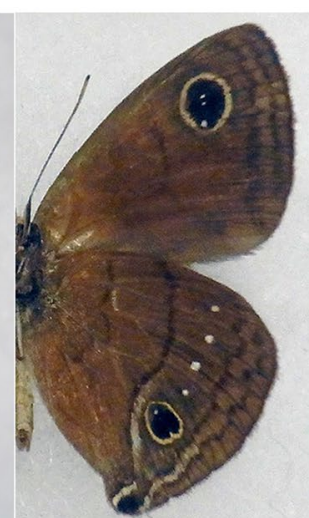

C. crypta

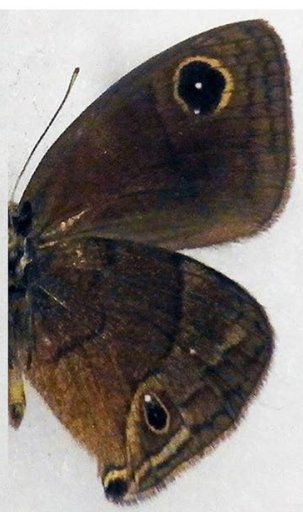

C. raburni

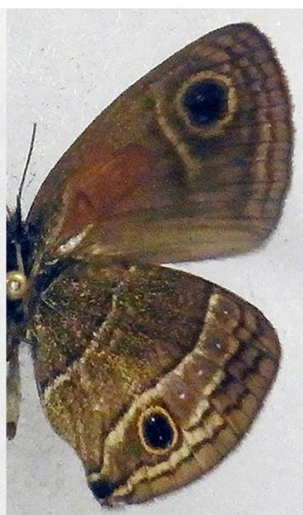

C. hysius

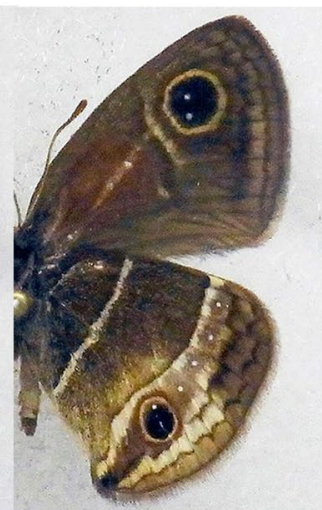

C. confusa

Fig. 6 Additional five Calisto species. Ventral sides are shown. Images are adjusted so that individuals appear at similar sizes. Scale bar 5 mm. This scale bar is applicable only to C. herophile 

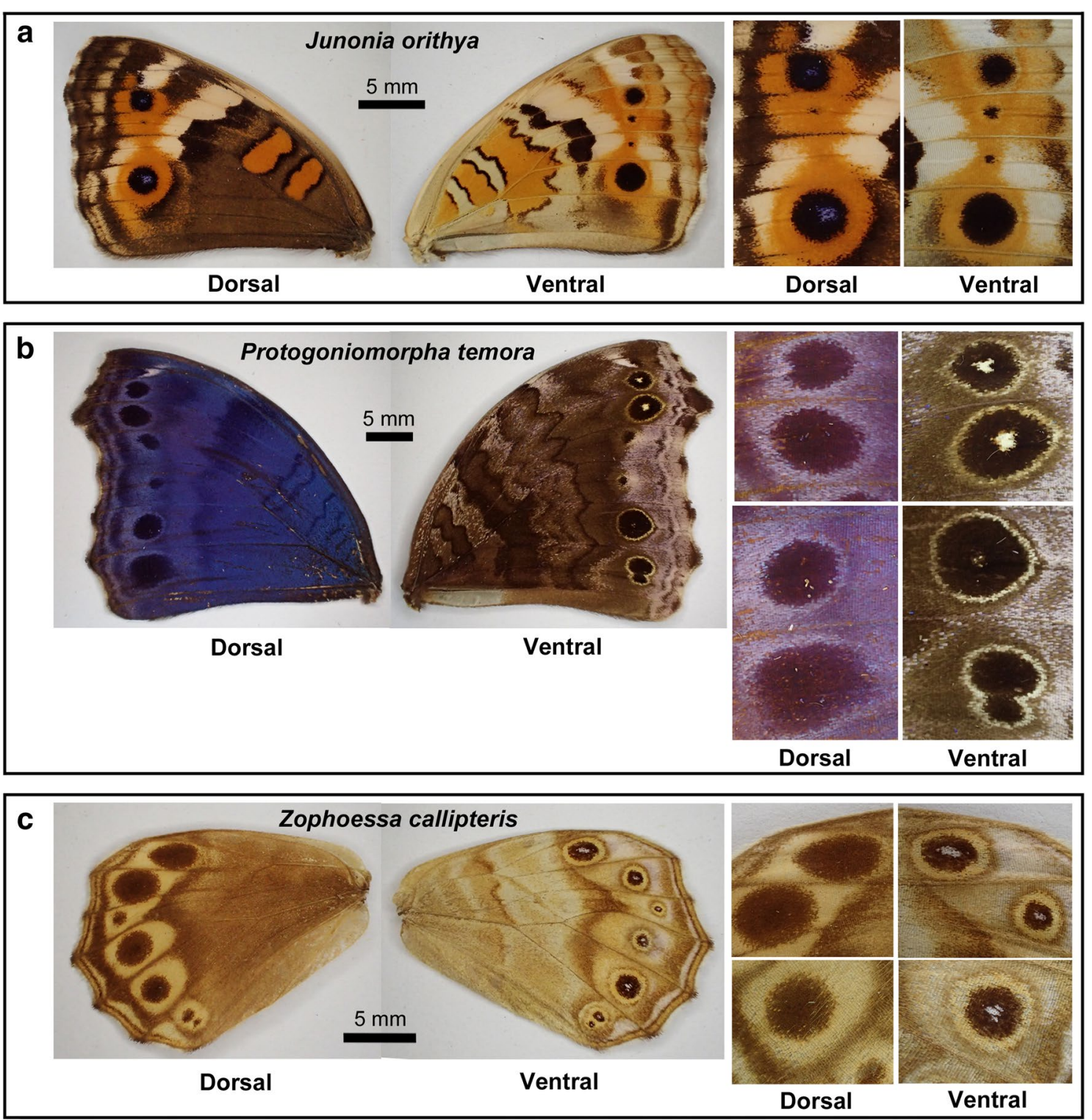

Fig. 7 Examples of "focus-less" eyespots. The dorsal and ventral sides are shown. Enlarged eyespot images are shown at the right side. Scale bars $5 \mathrm{~mm}$. a J. orithya. b Protogoniomorpha temora. c Zophoessa callipteris

pear-shaped eyespots that contained two or more white spots.

Assuming that color patterns are determined by organizing cells, each cluster of organizing cells for white spots and eyespot bodies appear to have behaved differently during development. We speculate that in the anterior forewing, one cluster of organizing cells was highly active and the other was weakly active or completely inactive for eyespot body determination. This means that completely inactive cells (regarding the inducing activity for an eyespot body) can still induce or differentiate into a white spot. If the area values of white spots represent morphogen levels for eyespot bodies, as a conventional gradient model predicts, both the $\mathrm{M}_{1}$ and $\mathrm{M}_{2}$ compartments in the anterior forewing should have comparable levels of morphogens (indeed, the $M_{1} / M_{2}$ ratio of white spots was 0.83 , meaning that the $M_{2}$ eyespot is slightly larger than the $M_{1}$ eyespot). In reality, however, the $M_{2}$ white spot is associated with either no or only a small eyespot body (that is, the $M_{1} / M_{2}$ ratio of eyespot bodies was infinitely large, meaning that the $\mathrm{M}_{1}$ eyespot body is much larger than the $\mathrm{M}_{2}$ eyespot body). Therefore, the area values of white spots do not indicate the activity levels of organizing centers for eyespot bodies in the 


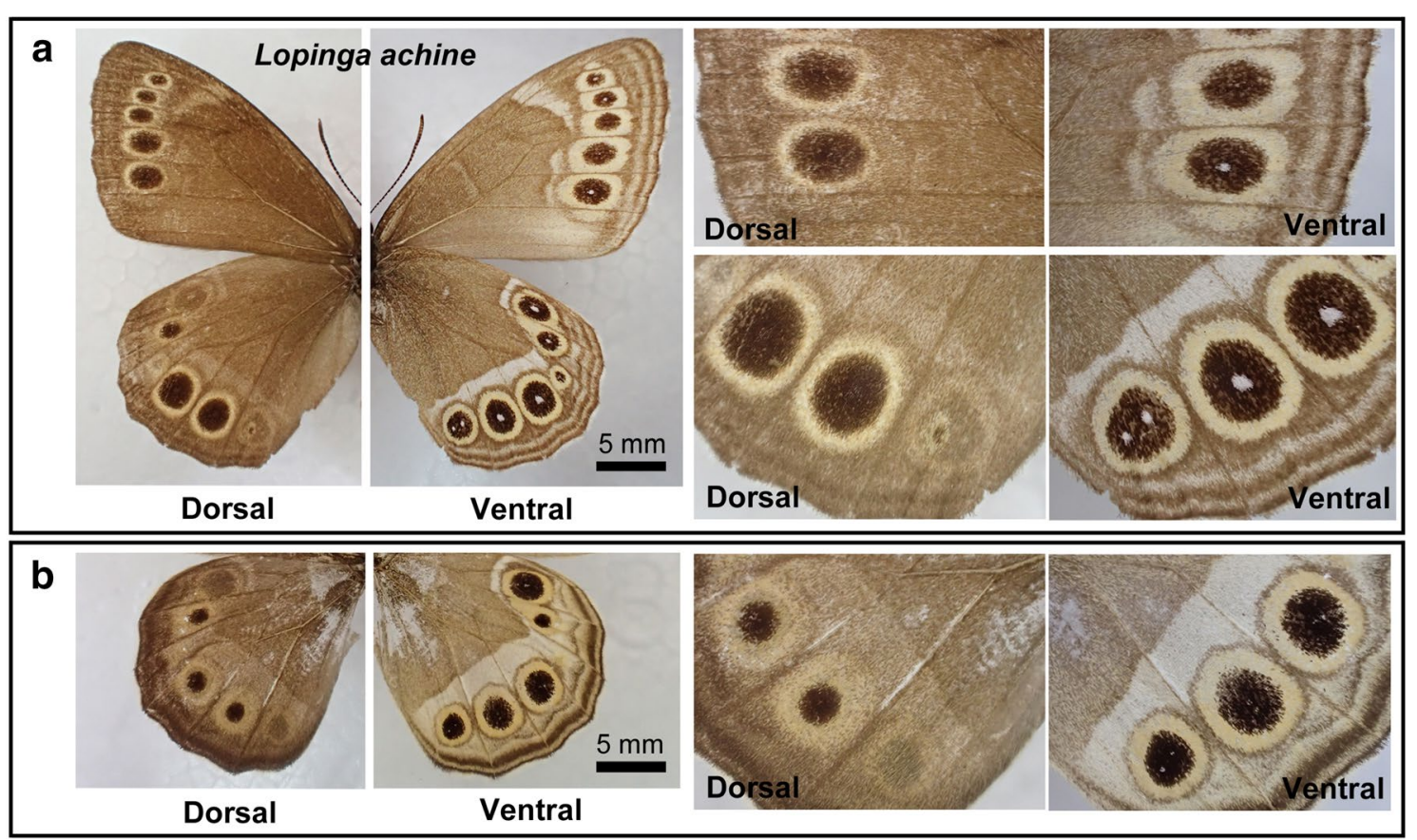

Fig. 8 Eyespots of Lopinga achine. Scale bars $5 \mathrm{~mm}$. a Normal wings. Most eyespots (but not all) on the ventral side have a white spot, but those on the dorsal side do not. $\mathbf{b}$ A mutant wing. The ventral eyespots have no or very small white spots

anterior forewing of $C$. tasajera, contrary to the expectation from a conventional gradient model. This conclusion is also relevant for the anterior and posterior hindwing regions in this species (see below).

In the anterior hindwing, there are two different solitary white spots. Interestingly, these two white spots are morphologically different: one is relatively small with clear boundary, and the other is relatively large with diffused boundary, showing the eyespot-independent morphological diversity of white spots. A difference in white patterns in adjacent compartments within the major eyespot of $J$. almana (Iwata and Otaki 2016) is probably a similar phenomenon. Similar white spot patterns were also found in some Cithaerias species such as C. pireta and in some Pierella species such as $P$. astyoche (Otaki 2011b).

In the posterior hindwing, we observed unique pearshaped eyespots. For the main eyespots of these pearshaped eyespots, the actual organizing center may be located at the physical center of the main eyespot and may be marked with a small white spot or not marked at all. The large proximal white spots exhibited little or no activity for inducing eyespot bodies. Quantitatively, the area values of white spots were not correlated with the black area values. These results, together with the results of the other two regions, argue that the white-inducing activity is independent of the eyespot-inducing activityat least in C. tasajera. This conclusion was supported by the eyespot and white spot patterns of other Calisto butterflies and other nymphalid butterflies.

\section{Morphological diversity of white spots}

Nijhout (1990) examined color patterns of 2208 species (330 genera) of nymphalid butterflies, in which [also in Chapter 7 of Nijhout (1991)] several types of eyespot focal morphology were discussed: arc-shaped foci in Morpho hecuba, double foci in Euptychia, fragmented foci in Lethe, and sparse patterns. Importantly, most of the white spot diverse patterns are successfully reproducible mathematically by a reaction-diffusion model (Nijhout 1990, 1991). Although the white spots of Calisto (i.e., the pear-shaped Calisto-type eyespots) were not specifically discussed, it was concluded that the relationship between the shape of the white area (or "focus") and the surrounding ocellus (i.e., eyespot body) is highly variable (Nijhout 1990), which is consistent with the present study. Moreover, Nijhout (1990) introduced "two point sources" along the midline as a part of a "toolbox" to produce diverse eyespot patterns, which is reminiscent of the pear-shaped Calisto-type eyespots. It is to be noted that the distortions of the pear-shaped eyespots of $\mathrm{Cal}$ isto, which have two or more foci along the midline, are very different from a common distortion of single-focus eyespots, which was explained by the two-gradient model (Nijhout 1978, 1981). 


\section{Mathematical models}

In Chapter 7 of the seminal book (Nijhout 1991) and also in the previous paper (Nijhout 1990), two mathematical models are presented for color pattern formation, one that determines the location of the organizing centers (source formation model) and a second that determines actual eyespots (eyespot formation model). The latter model is based on a morphogen gradient model as discussed in the "Background" section of this paper, while the former is a model for determining the position of the organizing centers (Nijhout 1990, 1991). The former model is given by reaction-diffusion equations based on the principle of "short-range activation and long-range inhibition" (Gierer and Meinhardt 1972; Meinhardt and Gierer 1974, 2000; Meinhardt 1982). In this model, activator concentration becomes high along the midline. This high midline region then retracts toward the wing margin, but a few high activation points are left behind. The multiple white spots along the midline found in the posterior hindwing of $C$. tasajera are therefore compatible with this model. The activator dots will then become white spots in C. tasajera. However, stable emergence of the white spots with and without eyespot bodies in particular compartments-as observed in the anterior forewing region in C. tasajera-is enigmatic.

Sekimura et al. (2015) recently reported successful simulation of the emergence of an eyespot organizing center in particular compartments but not in other compartments by changing boundary conditions. However, the emerging organizing centers in particular compartments may release morphogenic signals either for an eyespot body or for a white spot or both. In other words, considering the results of the present paper, what is specified in the source formation model (Nijhout 1990, 1991) is the location of immature cells that could differentiate either (1) into a white spot organizing center, or (2) into an eyespot body organizing center (without white spot), or (3) both. It will be interesting to see whether a model similar to that proposed in Sekimura et al. (2015) can explain these various immature-cell-fate options, as observed in the anterior forewing region of C. tasajera. Moreover, sparse patterns such as those observed in the anterior hindwing region of $C$. tasajera, which are common in nymphalid eyespots and white spots, should also be simulated in the future.

Genetic network simulations based on expression pattern studies successfully simulated developmental processes and final placement of eyespot focus (Evans and Marcus 2006; Marcus and Evans 2008). The successful simulation results are dependent on careful adjustments of expression thresholds. Evans and Marcus (2006) state that a subtle threshold adjustment could entirely eliminate eyespot development, resulting in an eyespot-less compartment. Furthermore, the irregular shape of eyespot foci in the comet and Cyclops mutants in B. anynana were successfully simulated (Marcus and Evans 2008).

In the eyespot of $B$. anynana, a white spot is placed at the center, signifying the location of organizing center for the entire eyespot. Thus, these simulation studies need no revision (regarding the $B$. anynana eyespot) based on the present results. However, similar but different simulations may be required to differentiate a white spot from an organizing center and to describe the behavior of white spots in C. tasajera.

\section{DIl expression in eyespot organizing centers}

A high $D l l$ expression level is found at the center of prospective eyespots in J. coenia [see Fig. 4, page 238 in Brakefield et al. (1996) or Fig. 6.4, page 167 in Carroll et al. (2004)]. The interpretation of this fact has been to consider $\mathrm{D} l l$ as an important regulatory gene for eyespot formation (Brakefield et al. 1996; Nijhout 1996). However, one should notice that the adult eyespots of $J$. coenia do not have a discrete white "focus" at the center. White scales are scattered along the proximal side of the eyespot. Thus, $\mathrm{Dll}$ expression appears to regulate eyespot bodies but not to specify the white area in this instance. This interpretation is likely also applicable to the case of $J$. almana, in which the largest scales are blue/black scales located at the central area of the eyespot, while white scales are located proximally (Iwata and Otaki 2016). A similar discussion can be found in Monteiro (2008); the presence or absence of white spot at the center does not signify the presence or absence of focal activity as an eyespot organizing center.

On the other hand, in the case of the dorsal forewing eyespots of $J$. orithya, which have distinct white (or strictly, bluish) focal areas, the size of the entire eyespot as well as the size of these white foci are only weakly correlated with the $D l l$ expression level (Adhikari and Otaki 2016). In this case, $D l l$ expression that regulates the size of eyespot bodies probably coincides to a certain extent with the expression of unknown genes that regulate the size of white areas. Indeed, white spots are not likely affected much in Dll-deleted wings (Zhang and Reed 2016).

\section{Structural versus pigment-based coloration}

The white coloration of white spots is structural, rather than pigment-based, in Junonia butterflies (Nijhout 1980b, 1991; Monteiro et al. 2015; Iwata and Otaki 2016). Because developmental processes of structural color production and pigment synthesis would be very different, an uncoupling of the white spots (i.e., structural color expression) from the eyespot bodies (i.e., pigment production) may be reasonable. Interestingly, probably because of the different synthetic pathways, it seems 
that pigment synthesis and structural color expression are able to coexist in a given cell to some extent, because brownish white scales are present in the anterior hindwing region in C. tasajera. Furthermore, colored foci are not rare in nymphalid butterflies. A good example is the dorsal forewing eyespots of $J$. orithya, which have bluish white foci. The coexistence of structural and pigmentbased coloration in focal spots certainly contributes to the diversity of "white spots" in nymphalid butterflies.

\section{Conclusions}

Eyespot body behavior and white spot behavior are different and separable, although the same cells may function to organize both in many instances. The size of white spots in adults does not necessarily reflect the degrees of organizing activity for eyespots. Because white coloration of white scales is structural rather than pigment-based, the differentiation mechanism for white scales may be independent from that for black or other pigmented scales.

\section{Authors' contributions}

JMO conceptualized the idea of this study, performed color pattern analysis and wrote the manuscript. MI took pictures of specimens and performed statistical analysis. Both authors read and approved the final manuscript.

\section{Acknowledgements}

The authors thank Nariaki Yamada and Haruo Takizawa for kindly allowing us to take pictures and to analyze them. We also thank members of the BCPH Unit of Molecular Physiology for discussions.

\section{Competing interests}

The authors declare that they have no competing interests.

\section{Availability of data and materials}

All data supporting the findings are shown in this paper.

\section{Funding}

This work was supported by the basic research budget of the University of the Ryukyus.

Received: 27 May 2016 Accepted: 29 July 2016

Published online: 08 August 2016

\section{References}

Adhikari K, Otaki JM (2016) A single-wing removal methods to assess correspondence between gene expression and phenotype in butterflies: a case of Distal-less. Zool Sci 33:13-20

Askew RR, Stafford PAVB (2008) Butterflies of the Cayman Islands. Apollo Books, Stenstrup

Beldade P, Brakefield PM (2002) The genetics and evo-devo of butterfly wing patterns. Nat Rev Genet 3:442-452

Beldade P, Brakefield PM, Long AD (2002) Contribution of Distal-less to quantitative variation in butterfly eyespots. Nature 415:315-318

Beldade P, French V, Brakefield PM (2008) Developmental and genetic mechanisms for evolutionary diversification of serial repeats: eyespot size in Bicyclus anynana butterflies. J Exp Zool Mol Dev Evol 310B:191-201

Brakefield PM, French V (1995) Eyespot development on butterfly wings: the epidermal response to damage. Dev Biol 168:98-111

Brakefield PM, Gates J, Keys D, Kesbeke F, Wijngaarden PJ, Monteiro A, French V, Carroll SB (1996) Development, plasticity and evolution of butterfly eyespot patterns. Nature 384:236-242
Brunetti CR, Selegue JE, Monteiro A, French V, Brakefield PM, Carroll SB (2001) The generation and diversification of butterfly eyespot color patterns. Curr Biol 11:1578-1585

Carroll SB, Gates J, Keys DN, Paddock SW, Panganiban GE, Selegue JE, Williams JA (1994) Pattern formation and eyespots determination in butterfly wings. Science 265:109-114

Carroll SB, Grenier JK, Weatherbee SD (2004) From DNA to diversity. Molecular genetics and the evolution of animal design, 2nd edn. Wiley-Blackwell, Oxford

Dhungel B, Otaki JM (2009) Local pharmacological effects of tungstate on the color-pattern determination of butterfly wings: a possible relationship between the eyespot and parafocal element. Zool Sci 26:758-764

Dhungel B, Otaki JM (2013) Morphometric analysis of nymphalid butterfly wings: number, size and arrangement of scales, and their implications for tissue-size determination. Entomol Sci 17:207-218

Dhungel B, Ohno Y, Matayoshi R, Otaki JM (2013) Baculovirus-mediated gene transfer in butterfly wings in vivo: an efficient expression system with an anti-gp64 antibody. BMC Biotechnol 13:27

Dhungel B, Ohno Y, Matayoshi R, Iwasaki M, Taira W, Adhikari K, Gurung R, Otak JM (2016) Distal-less induces elemental color patterns in Junonia butterfly wings. Zool Lett 2:4

Evans TM, Marcus JM (2006) A simulation study of the genetic regulatory hierarchy for butterfly eyespot focus determination. Evol Dev 8:273-283

French V, Brakefield PM (1992) The development of eyespot patterns on butterfly wings: morphogen sources or sinks? Development 116:103-109

French V, Brakefield PM (1995) Eyespot development on butterfly wings: the focal signal. Dev Biol 168:112-123

Gierer A, Meinhardt H (1972) A theory of biological pattern formation. Kybernetik 12:30-39

González FL, Schwartz A, Wetherbee DK (1991) A new species of Calisto (Lepidoptera: Satyridae) of the lyceia complex on Hispaniola. Milwaukee Public Mus Contr Biol Geol 80:1-8

Hedges SB, Johnson K (1994) Calisto tasajera in the Hispaniolan Cordillera Central (Lepidoptera: Nymphalidae: Satyrinae). Trop Lepid 5:93-94

Henke K (1946) Ueber die verschiendenen Zellteilungsvorgänge in der Entwicklung des beschuppten Flügelepithelis der Mehlmotte Ephestina kühniella Z. Biol Zent 65:120-135 (in German)

Hiyama A, Taira W, Otaki JM (2012) Color-pattern evolution in response to environmental stress in butterflies. Front Genet 3:15

Iwata M, Otaki JM (2016) Spatial patterns of correlated scale size and scale color in relation to color pattern elements in butterfly wings. J Insect Physiol 85:32-45

Iwata M, Ohno Y, Otaki JM (2014) Real-time in vivo imaging of butterfly wing development: revealing the cellular dynamics of the pupal wing tissue. PLOS ONE 9:e89500

Keys DN, Lewis DL, Selegue JE, Pearson BJ, Goodrich LV, Johnson RL, Gates J, Scott MP, Carroll SB (1999) Recruitment of a hedgehog regulatory circuit in butterfly eyespot evolution. Science 283:532-534

Kusaba K, Otaki JM (2009) Positional dependence of scale size and shape in butterfly wings: wing-wide phenotypic coordination of color-pattern elements and background. J Insect Physiol 55:174-182

Mahdi SHA, Gima S, Tomita Y, Yamasaki H, Otaki JM (2010) Physiological characterization of the cold-shock-induced humoral factor for wing color-pattern changes in butterflies. J Insect Physiol 56:1022-1031

Mahdi SHA, Yamasaki H, Otaki JM (2011) Heat-shock-induced color-pattern changes of the blue pansy butterfly Junonia orithya: physiological and evolutionary implications. J Therm Biol 36:312-321

Marcus JM, Evans TM (2008) A simulation study of mutations in the genetic regulatory hierarchy for butterfly eyespot focus determination. BioSystems 93:250-255

Matos-Maraví P, Águila RN, Peña C, Miller JY, Sourakov A, Wahlberg N (2014) Causes of endemic radiation in the Caribbean: evidence from the historical biogeography and diversification of the butterfly genus Calisto (Nymphalidae: Satyrinae: Satyrini). BMC Evol Biol 14:199

Mayer AG (1896) The development of the wing scales and their pigment in butterflies and moths. Bull Mus Comp Zoöl Harvard College XXIX(5):219-236

Meinhardt $H$ (1982) Models of biological pattern formation. Academic Press, London 
Meinhardt H, Gierer A (1974) Applications of a theory of biological pattern formation based on lateral inhibition. J Cell Sci 15:321-346

Meinhardt H, Gierer A (2000) Pattern formation by local self-activation and lateral inhibition. BioEssays 22:753-760

Miller JY, Miller LD (2001) The biogeography of the West Indian butterflies (Lepidoptera): an application of a vicariance/dispersalist model. In: Woods CA, Sergile FE, Press CRC (eds) Biogeography of the West Indies: patterns and perspectives, 2nd edn. Boca, Raton, pp 127-155

Monteiro A (2008) Alternative models for the evolution of eyespots and of serial homology on lepidopteran wings. BioEssays 30:358-366

Monteiro A, French V, Smit G, Brakefield PM, Metz JA (2001) Butterfly eyespot patterns: evidence for specification by a morphogen diffusion gradient. Acta Biotheor 49:77-88

Monteiro A, Glaser G, Stockslager S, Glansdorp N, Ramos D (2006) Comparative insights into questions of lepidopteran wing pattern homology. BMC Dev Biol 6:52

Monteiro A, Chen B, Ramos D, Oliver JC, Tong X, Guo M, Wang W-K, Fazzino L, Kamal $F(2013)$ Distal-less regulates eyespot patterns and melanization in Bicyclus butterflies. J Exp Zool B Mol Dev Evol 320:321-331

Monteiro A, Tong X, Bear A, Liew SF, Bhardwaj S, Wasik BR, Dinwiddie A, Bastianelli C, Cheong WF, Wenk MR, Cao H, Prudic KL (2015) Differential expression of ecdysone receptor leads to variation in phenotypic plasticity across serial homologies. PLoS Genet 11:e1005529

Nijhout HF (1978) Wing pattern formation in lepidoptera: a model. J Exp Zool 206:119-136

Nijhout HF (1980a) Pattern formation on lepidopteran wings: determination of an eyespot. Dev Biol 80:267-274

Nijhout HF (1980b) Ontogeny of the color pattern on the wings of Precis coenia (Lepidoptera: Nymphalidae). Dev Biol 80:275-288

Nijhout HF (1981) The color patterns of butterflies and moths. Sci Am 254:145-151

Nijhout HF (1984) Colour pattern modification by coldshock in Lepidoptera. J Embryol Exp Morphol 81:287-305

Nijhout HF (1985) Cautery-induced colour patterns in Precis coenia (Lepidoptera: Nymphalidae). J Embryol Exp Morphol 86:191-203

Nijhout HF (1990) A comprehensive model for color pattern formation in butterflies. Proc R Soc Lond Ser B 239:81-113

Nijhout HF (1991) The development and evolution of butterfly wing patterns. Smithsonian Institution Press, Washington

Nijhout HF (1994) Genes on the wing. Science 265:44-45

Nijhout HF (1996) Focus on butterfly eyespot development. Nature 384:209-210

Nijhout HF (2001) Elements of butterfly wing patterns. J Exp Zool 291:213-225

Ohno Y, Otaki JM (2015a) Live cell imaging of butterfly pupal and larval wings in vivo. PLOS ONE 10:e0128332

Ohno Y, Otaki JM (2015b) Spontaneous long-range calcium waves in developing butterfly wings. BMC Dev Biol 15:17

Otaki JM (1998) Color-pattern modifications of butterfly wings induced by transfusion and oxyanions. J Insect Physiol 44:1181-1190

Otaki JM (2007) Reversed type of color-pattern modifications of butterfly wings: a physiological mechanisms of wing-wide color-pattern determination. J Insect Physiol 53:526-537

Otaki JM (2008a) Physiologically induced color-pattern changes in butterfly wings: mechanistic and evolutionary implications. J Insect Physiol 54:1099-1112

Otaki JM (2008b) Phenotypic plasticity of wing color patterns revealed by temperature and chemical applications in a nymphalid butterfly Vanessa indica. J Therm Biol 33:128-139

Otaki JM (2009) Color-pattern analysis of parafocal elements in butterfly wings. Entomol Sci 12:74-83
Otaki JM (2011a) Artificially induced changes of butterfly wing colour patterns: dynamic signal interactions in eyespot development. Sci Rep 1:111

Otaki JM (2011b) Color-pattern analysis of eyespots in butterfly wings: a critical examination of morphogen gradient models. Zool Sci 28:403-413

Otaki JM (2011c) Generation of butterfly wing eyespot patterns: a model for morphological determination of eyespot and parafocal element. Zool Sci 28:817-827

Otaki JM (2012a) Colour pattern analysis of nymphalid butterfly wings: revision of the nymphalid groundplan. Zool Sci 29:568-576

Otaki JM (2012b) Structural analysis of eyespots: dynamics of morphogenic signals that govern elemental positions in butterfly wings. BMC Syst Biol 6:17

Otaki JM, Yamamoto H (2004a) Species-specific color-pattern modifications of butterfly wings. Dev Growth Differ 46:1-14

Otaki JM, Yamamoto H (2004b) Color-pattern modifications and speciation in butterflies of the genus Vanessa and its related genera Cynthia and Bassaris. Zool Sci 21:967-976

Otaki JM, Ogasawara T, Yamamoto H (2005a) Morphological comparison of pupal wing cuticle patterns in butterflies. Zool Sci 22:21-34

Otaki JM, Ogasawara T, Yamamoto H (2005b) Tungstate-induced color-pattern modifications of butterfly wings are independent of stress response and ecdysteroid effect. Zool Sci 22:635-644

Otaki JM, Hiyama A, Iwata M, Kudo T (2010) Phenotypic plasticity in the rangemargin population of the lycaenid butterfly Zizeeria maha. BMC Evol Biol 10:252

Reed RD, Serfas MS (2004) Butterfly wing pattern evolution is associated with changes in a Notch/Distal-less temporal pattern formation process. Curr Biol 14:1159-1166

Saenko SV, Marialva MS, Beldade P (2011) Involvement of the conserved Hox gene Antennapedia in the development and evolution of a novel trait. EvoDevo 2:9

Schneider CA, Rasband WS, Eliceiri KW (2012) NIH image to ImageJ: 25 years of image analysis. Nat Methods 9:671-675

Sekimura T, Venkataraman C, Madzvamuse A (2015) A model for selection of eyespots on butterfly wings. PLOS ONE 10:e0141434

Serfas MS, Carroll SB (2005) Pharmacologic approaches to butterfly wing patterning: sulfated polysaccharides mimic or antagonize cold shock and alter the interpretation of gradients of positional information. Dev Biol 287:416-424

Smith DS, Miller LD, Miller JY (1994) The butterflies of the West Indies and South Florida. Oxford University Press, Oxford

Sondhi KH (1963) The biological foundations of animal patterns. Q Rev Biol 38:289-327

Sourakov A, Zakharov EV (2011) "Darwin's butterflies"? DNA barcoding and the radiation of the endemic Caribbean butterfly genus Calisto (Lepidoptera, Nymphalidae, Satyrinae). Comp Cytogenet 5:191-210

Taira W, Otaki JM (2016) Butterfly wings are three-dimensional: pupal cuticle focal spots and their associated structures in Junonia butterflies. PLoS ONE 11:e0146348

Taira W, Kinjo S, Otaki JM (2015) The marginal band system in the nymphalid butterfly wings. Zool Sci 32:38-46

Tong X, Lindemann A, Monteiro A (2012) Differential involvement of Hedgehog signaling in butterfly wing and eyespot development. PLOS ONE 7:e51087

Zhang L, Reed RD (2016) Genome editing in butterflies reveals that spalt promotes and Distal-less represses eyespot color patterns. Nat Commun 7:11769 